\title{
Reutilización de aguas grises mediante sistema tecnológico alternativo: evaluación bacteriológica de las mismas
}

Sara C. Daives ${ }^{\mathrm{a} 1}$; Beatriz S. Garzón ${ }^{\mathrm{b} 2}$; Leonardo Paterlini ${ }^{\mathrm{b} 3}$; Nancy L. Correa ${ }^{\mathrm{a} 4}$; Graciela L. Sacur ${ }^{25}$

\section{Resumen:}

La escasez del agua es un problema planetario. Reciclando aguas grises se pueden reutilizar cuando no es imprescindible agua potable, como en inodoros, generando un sistema tecnológico innovador. Para generar el dispositivo se analizaron dos tipos de materiales, fibra de vidrio y acero inoxidable. Se evaluó el sistema utilizando muestras de agua pre y post filtrado, mediante un filtro de tela de fibra plástica para retener sedimentos macroscópicos. Se empleó solu- ción de policloruro de aluminio para clarificar y pastillas de cloro para descontaminar. Se realizó evaluación bacteriológica de estas aguas con medios de cultivo específicos para Coliformes totales y Coliformes fecales. Se seleccionó el sistema construido con fibra de vidrio. Las muestras de agua post filtro y post desinfectante no desarrollaron bacterias. Si bien el acero inoxidable, es resistente a la corrosión e impactos, es higiénico y fácil de moldear, su desventaja es su costo. Se optó por el material de fibra de vidrio que

\footnotetext{
a Facultad de Bioquímica, Química y Farmacia - Secretaria de Ciencia Arte e Innovación Tecnológica, Universidad Nacional de Tucumán. San Lorenzo 456

b Facultad de Arquitectura y Urbanismo - Secretaria de Ciencia Arte e Innovación Tecnológica, Universidad Nacional de Tucumán. CoNICET. Tel. 3815176103-0381-4364141

${ }^{1}$ Profesora Adjunta Cátedra de Toxicología, FBQF, UNT. Integrante Proyecto FAU-SCAIT, UNT. cristinadaives@hotmail.com

2 Profesora Adjunta Cátedra AAII, IAA, FAU, UNT. Investigadora Independiente CONICET. Directora Proyecto FAU-SCAIT, UNT. bgarzon@gmail.com

${ }^{3}$ Seminarista Cátedra AAII, IAA, FAU, UNT. Becario CONICET. Integrante. Proyecto FAU-SCAIT, UNT. paterlinileonardo@gmail.com

${ }_{4}^{4}$ JTP Cátedra de Toxicología, FBQF, UNT. Integrante Proyecto FAU-SCAIT, UNT. nancylorenacorrea@yahoo.com.ar ${ }_{5}^{5}$ JTP Cátedra de Toxicología, FBQF, UNT. Integrante Proyecto FAU-SCAIT, UNT. gracielasacur@hotmail.com
} 
es maleable, dúctil, más liviano y de menor costo. E1 sistema desarrollado es adaptable y asequible, convirtiéndolo en un producto adoptable en diferentes tipos de objetos arquitectónicos y, sustentables posibilitando el cuidado del ambiente.

Palabras clave: Aguas Grises, Reutilización, Cuidado Ambiental.

\section{Summary:}

The shortage of water is a planetary problem. Recycling gray water can be reused when it is not essential drinking water, as in toilets, generating an innovative technological system. Two types of materials, fiberglass and stainless steel, were analyzed to generate the device. The system was evaluated using pre-and post-filtered water samples, using a plastic fiber cloth filter to retain macroscopic sediments. Aluminum polychloride solution was used to clarify and chlorine tablets to decontaminate. Bacteriological evaluation of these waters was carried out with specific culture media for total coliforms and fecal coliforms. The system constructed with fiberglass was selected. Post-filter and post-disinfectant water samples did not develop bacteria. While stainless steel is resistant to corrosion and impacts, is bygienic and easy to mold, its disadvantage is its cost. We chose the fiberglass material that is malleable, ductile, lighter and lower cost. The developed system is adaptable and affordable, converting it into an adoptable product in different types of architectural objects and, sustainably enabling the care of the environment.
Keywords: Gray Waters, Reuse, Environmental Care.

\section{Introducción:}

La escasez de agua es una problemática que afecta a todo el planeta; está influenciada por el cambio climático y la gestión de los recursos hídricos principalmente, por lo que se debe hacer un enfoque global e integrador con la política de protección ambiental y promover la gestión conjunta de cantidad y calidad del agua. Es necesario imponer prácticas sustentables en actividades como agricultura, ganadería, industrias, etc. para que no se haga uso indiscriminado de recursos hídricos y en situaciones de escasez deben evitarse las extracciones descontroladas de aguas superficiales y subterráneas que degraden los ecosistemas y atenten contra la sustentabilidad de los acuíferos. La reutilización del agua brinda importantes beneficios sociales, productivos y ambientales; el reuso de aguas residuales proveniente de centros urbanos e industriales para riego en el sector agrícola o de aguas residuales domiciliarias para usos domiciliarios, constituyen acciones conducentes al uso racional y sustentable del recurso. Un 3\% del agua del planeta es agua dulce, el resto es toda agua salada presente en los océanos. De ese porcentaje de agua dulce, solo un $0.003 \%$ puede ser empleada para consumo humano pues el resto está retenida en glaciares, lo que la inutiliza como fuente de consumo humano. Existen pobladores cuyo hábitat tiene grandes dificultades para obtener agua potable y en cantidades necesarias para la vida. 
Por ello, es importante reutilizar aguas, en particular, aquellas que se definen como aguas grises, provenientes de duchas, bañaderas y lavabos. El reciclaje o tratamiento de aguas grises permite reutilizarlas para usos como inodoros, riego, lavadoras o limpieza de suelos o vehículos en los que no es imprescindible que sea agua potable.

\section{Objetivos:}

a) General, reutilizar un elemento esencial y a la vez escaso como es el agua potable, generando y promoviendo, un sistema tecnológico innovador y b) Específicos, generar un sistema tecnológico alternativo para reutilizar aguas grises provenientes de lavabos; evaluar sistemas de filtrado, clarificación y descontaminación; evaluar bacteriológicamente las aguas y el funcionamiento del sistema todo.

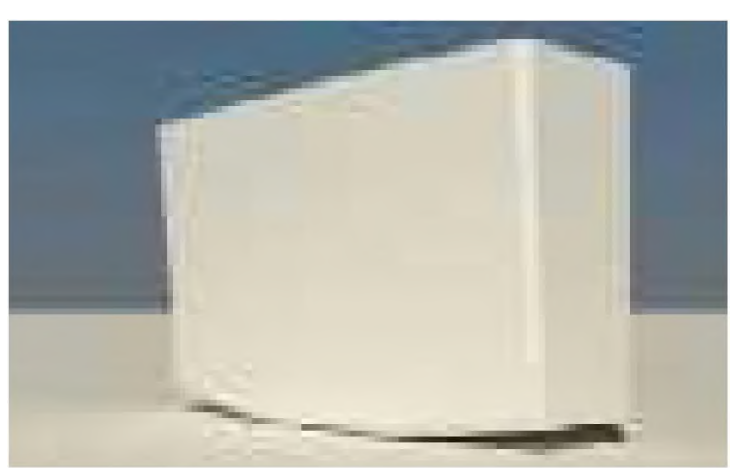

Figura 1: Prototipo de depósito de agua de inodoro (mochila) especialmente diseñado.

\section{Materiales y Métodos:}

Para la generación de este dispositivo (Figura 1), se analizaron materiales y componentes cuyas características técnicas faciliten su fabricación y aseguren durabilidad en el tiempo en sanitarios con alto nivel de humedad, además de poder generar un recipiente impermeable capaz de albergar el agua de reutilización. Los materiales analizados fueron acero inoxidable y fibra de vidrio.

El acero inoxidable brinda ventajas en resistencia a la corrosión y oxidación, buena higiene-limpieza, estética, excelente soldabilidad, facilidad para moldear y mayor sensibilidad hacia los problemas ecológicos; su desventaja es su mayor costo.

La fibra de vidrio posee buenas características de maleabilidad y ductilidad, fácil ejecución y permite la producción en

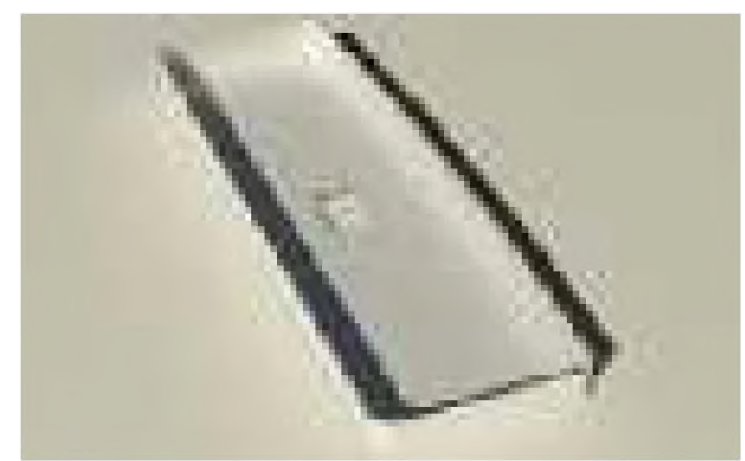

serie. Se construye una matriz del elemento a partir del cual se le van haciendo sucesivas copias como sean necesarias (Figura 2); permite un diseño personalizado, excelente terminación, bajo peso y bajo costo.

Una tubería de PVC que contiene en su interior un filtro para grasas y partículas macroscópicas, consistente en una tela de fibra plástica tipo Unifilter, conecta el dispositivo a la descarga del lavabo mediante. La reutilización de esta agua para la mochila del inodoro, no requiere que ésta sea potable, pero, considerando que las aguas grises se pueden transformar en "aguas 

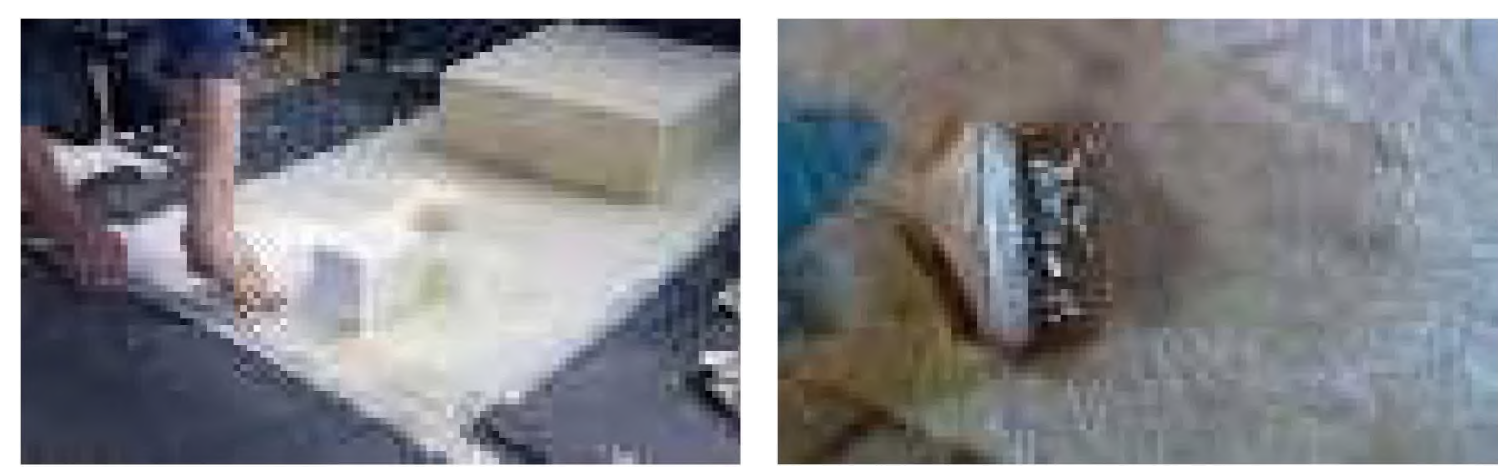

Figura 2: Fibra de Vidrio: Proceso de Aplicación de la Fibra de Vidrio.

negras" si son retenidas sin oxigenar, aún en un corto período de tiempo y que, si bien las aguas grises no tienen mal olor inmediatamente después de ser descargadas, cuando quedan en reposo por unas horas, los microorganismos, consumen rápidamente el oxígeno disponible permitiendo el crecimiento de bacterias anaeróbicas, que además de dar mal olor, podrían crear un ambiente propicio para el desarrollo de otros patógenos humanos. Para la clarificación y descontaminación de esta agua se empleó una pastilla potabilizadora y luego de 24 hs se realizó el control bacteriológico para asegurar la asepsia y baja turbidez del agua que será usada en el inodoro. El dispositivo permitiría reutilizar aproximadamente $15 \mathrm{l} / \mathrm{d} /$ persona, generando un ahorro mensual de 1800 litros en una vivienda de 4 personas.

Resultados de la experimentación y evaluación del sistema: funcionamiento del dispositivo. El sistema permitirá reutilizar el agua proveniente del lavabo del baño, básicamente, agua con jabón utilizada en la higiene personal de manos, boca y cara y que como tal puede contener bacterias, virus, parásitos y restos orgánicos. $\mathrm{E} 1$ mismo se encuentra unido a un sistema de cañerías que desde la descarga del lavabo lleva el agua gris, por gravedad, hacia el depósito de agua del inodoro (mochila) especialmente diseñado. El ingreso del agua gris es por la parte posterior de la misma, quedando todas las cañerías embutidas en la pared. Para realizar el ensayo se colectó agua de un día normal de uso del lavatorio de un baño; 3 litros de esa agua se vertieron en la mochila y se completó el volumen con agua potable, pues que en estas proporciones trabajará la mochila, con 3 litros de agua gris reutilizada y 9 litros de agua potable. Al ingreso del agua gris se produce un filtrado a través de un filtro para grasas donde quedan retenidos los sedimentos macroscópicos como restos de jabón, dentífrico, células epiteliales de descamación, materias orgánicas y organismos causantes de enfermedades que podrían haber sido arrastrados con el agua que proviene del lavatorio. Se recolectaron muestras del agua gris antes y después del filtrado para ser evaluadas bacteriológicamente como "muestra basal" y "muestra post 

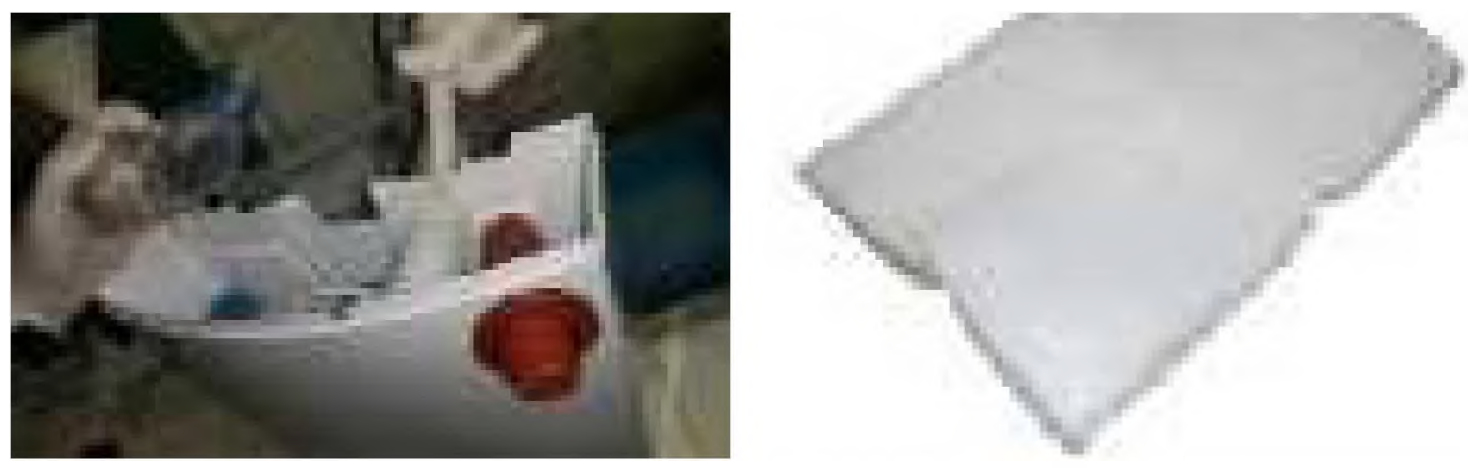

Figura 3: Experimentación con Tela de fibra tipo Unifilter

filtrado". Para el filtrado, se empleó un material consistente en una tela de fibra plástica del tipo de las usadas en campanas de extracción (Figura 3).

Una vez que el agua ya filtrada, se coloca dentro de la mochila, desde un acceso frontal, se colocan pastillas potabilizadoras. Ambos procesos evitan el desarrollo de gérmenes en general y bacterias de transmisión fecal- oral en particular. En cada experimento y tratamiento secuencial de las aguas grises, se evaluaron bacteriológicamente las aguas, básicamente en las siguientes etapas (Figura 4):

\section{$\mathbf{1}^{\mathbf{a}}$.- Previa al filtrado.}

$2^{\mathbf{a}}$.- Post filtrado. La muestra de agua resultante, se evaluó bacteriológicamente, cultivándola en medios adecuados para evaluar presencia de gérmenes.

3a.- Para mejorar el aspecto macroscópico del agua se experimentó un tratamiento de clarificación, con el agregado de una solución de policloruro de aluminio, con lo que la materia floculó y sedimentó por su propio peso. Se visualizó la disminución de turbidez en las aguas y se cultivó en medios adecuados para la evaluación de gérmenes.

4a.- Para la desinfección se agregó una pastilla de cloro y se dejó en reposo 8 hs; se la mezcló tratada con agua potable en la proporción de 3/9; se dejó reposar en la mochila 24 hs y se tomaron muestras para analizar; una con pastilla potabilizadora y otra con floculante decantador (cuánta materia sólida contenía) para usar o no decantador.
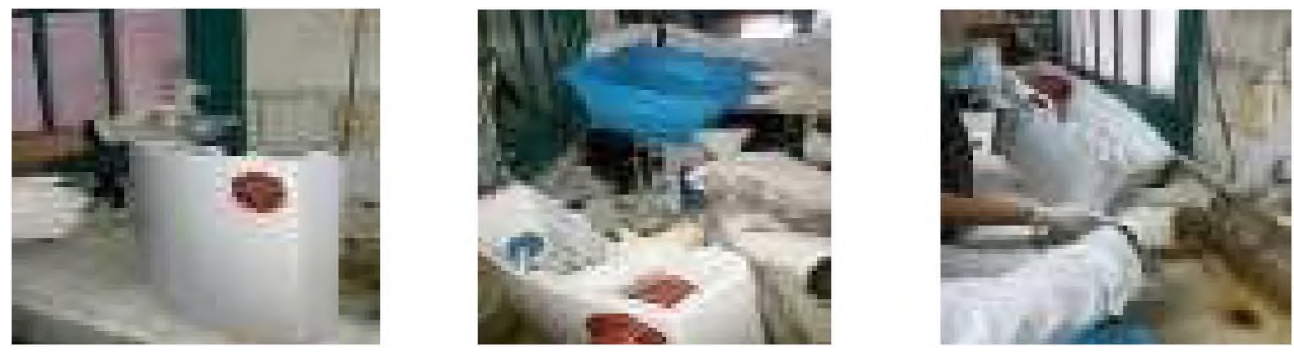

Figura 4: funcionamiento del prototipo y del tratamiento de las aguas grises. 
Ensayos bacteriológicos en laboratorio: Para la evaluación microbiológica de las aguas en todo el procedimiento se emplearon medios de cultivo específicos: a) Para Coliformes totales, medio Endo, incubando a $37^{\circ} \mathrm{C}, 24$ horas y b) Para Coliformes Fecales medio MFC, incubando en estufa a $44.5^{\circ} \mathrm{C}, 24$ horas.

Resultados del Control bacteriológico: Solo se realizaron muestreos para evaluación bacteriológica en tres de ellos, pues la muestra post floculante presentaba elevada turbidez, con la consiguiente obturación de la membrana filtrante: a) Muestra 1: Basal; b) Muestra 2: Post Filtro; c) Muestra 3: Post Desinfectante.

En muestras 2 y 3 no hubo desarro1lo de colonias o Unidades Formadoras de Colonias (UFC) (Figura 5), por lo que el Resultado fue: Coliformes fecales y totales: $0 \mathrm{UFC} / \mathrm{ml}$
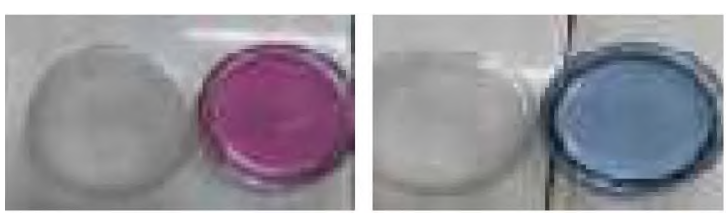

Figura 5: Control bacteriológico negativo.

En muestras 2 y 3 no bubo UFC

\section{Discusión:}

Los productos y dispositivos que permiten la reutilización de aguas grises existentes en mercado, requieren energías alternativas para funcionar y que encarecen el producto, como elementos de bombeo, purificadores químicos y espacio para su instalación. Nuestra propuesta permite usar estos dispositivos, optimizando la energía, en mínimos espacios de uso brindando una solución óptima al usuario.

\section{Conclusiones:}

El sistema desarrollado es "adaptable" y "asequible"; presenta facilidad constructiva y de colocación en obra, siendo un "producto adoptable" en diferentes tipos arquitectónicos, libre de contaminantes y en un producto "estéril y sustentable", posibilitando el cuidado del medio ambiente.

\section{Bibliografía}

http://www.cohife.org

Colangelo, Carlos H.; Abbiatti, Humberto N. (2003).

"Contaminación Ambiental: Análisis Multidisciplinario", pp 88-89 y 96-100. Ediciones Praia. Argentina.

G.Tyler Miller,Jr. (2003).“Ciencia Ambiental”. $5^{\circ}$ ed. 333337. Ed Color S. A. México

Pasquali, Ricardo C. (2003). Química Ambiental. $\mathrm{I}^{\circ}$ Edición.147/50. Bs As.Akadia Ed.

http://www.bajatec.net/agua-captacion-conservacion/filtros-de-arena-para-aguas-grises

Ing. Julio Moscoso (2001). Tratamiento y Uso de Aguas Residuales Domésticas CEPIS / OPS / OMS.

http://www.sartorius.com/es/productos/laboratorio/filtros/cartuchos-de-extraccion

David Bermejo Arnaldos. (2008). Reutilización de aguas residuales domésticas. Universitat d'Alacant. Universidad de Alicante. Canarias.

Grupo de trabajo Comisión Sectorial de Aguas Grises. (2012). Guía Técnica Española de Recomendaciones para Reciclaje de Aguas Grises. Aqua España. Madrid. Es 